\title{
SARS-CoV-2 Infection During Induction Chemotherapy in a Child With High-risk T-Cell Acute Lymphoblastic Leukemia (T-ALL)
}

\author{
Tobias M. Dantonello, MD, ${ }^{*}$ Mutlu Kartal-Kaess, MD, * \\ Christoph Aebi, MD, PhD, $\dagger$ Franziska Suter-Riniker, PhD, $\neq$ \\ Jasmin D. Busch, MD, $\S$ Susanne Kubetzko, PhD,\| \\ Jean-Pierre Bourquin, MD, PhD, $\|$ and Jochen Roessler, MD*
}

\begin{abstract}
Summary: The clinical course of SARS-CoV-2 infection (COVID19) in children with hematologic malignancies is unclear. We describe the diagnosis, treatment and outcome of a 4-year-old boy with high-risk acute lymphoblastic leukemia and COVID-19. Regardless of immunosuppressive induction chemotherapy his symptoms remained moderate. He received only supportive treatment. Seroconversion occurred in a similar period as in immunocompetent adults. Despite prolonged myelosuppression he did neither acquire secondary infections nor did the treatment delay caused by the infection have a measurable negative impact on the residual disease of acute lymphoblastic leukemia. Intriguingly, residual leukemia even decreased even though he did not receive any antileukemic therapy.
\end{abstract}

Key Words: SARS-CoV-2, COVID-19, pediatric hematology, acute lymphoblastic leukemia

(J Pediatr Hematol Oncol 2020;00:000-000)

\section{BACKGROUND}

Infections with the novel coronavirus (SARS-CoV-2, COVID-19 disease) have a milder clinical course in children compared with adults. ${ }^{1,2}$ Even though presence of comorbid illnesses increases the risk for death among adults with COVID-19, 3,4 it is unclear if these increased risks also apply to children receiving cytotoxic therapies. There are only few publications mainly about patients with solid tumors or during nonintensive chemotherapies. These children had mild disease. $^{5-7}$ One exception is a boy with T-cell acute lymphoblastic leukemia (T-ALL) receiving maintenance chemotherapy in Wuhan with SARS-CoV-2 and influenza A infection. He developed respiratory failure requiring mechanical ventilation and had not recovered at the time of the report. $1,8,9$

Here, we describe the course of COVID-19 including diagnosis, treatment and outcome of a 4-year-old boy with high-risk T-ALL and the impact of the infection on the leukemia.

Received for publication May 15, 2020; accepted August 18, 2020

From the *Division of Pediatric Hematology and Oncology; †Division

of Pediatric Infectiology, Department of Pediatrics; §Department of

Diagnostic, Interventional and Pediatric Radiology, Bern University

Hospital; IInstitute for Infectious Diseases, University of Bern,

Bern; and ||Division of Oncology and Children's Research Centre,

University Children's Hospital Zurich, Zurich, Switzerland.

The authors declare no conflict of interest.

Reprints: Tobias M. Dantonello, MD, Division of Pediatric Hematology and Oncology, Department of Pediatrics, Bern University Hospital,

Freiburgstrasse 10, Bern CH-3010, Switzerland (e-mail: tobias. dantonello@insel.ch).

Copyright (C) 2020 Wolters Kluwer Health, Inc. All rights reserved.

\section{OBSERVATION (CASE REPORT)}

In January 2020, a 4-year-old boy was diagnosed with T-ALL. He had been healthy otherwise until then and had received all recommended vaccinations. He started treatment according to the trial AIEOP-BFM ALL 2017 (EudraCT 2016-001935-12). In quantitative polymerase chain reaction (PCR) analysis of the junctional regions of rearranged immunoglobulin and T-cell receptor genes (Ig/TCR PCR) he showed still positive minimal residual disease (MRD) values of $1.0 \mathrm{E}-3$ in the bone marrow at the end of the first part of induction therapy after 33 days..$^{10}$ Accordingly, his therapy response stratified him into the nonstandard risk-group.

On March 19 (illness day 0, ie, Day 0), he was admitted with fever up to $39.2^{\circ} \mathrm{C}$. At that date, he had been neutropenic for 14 days (ie, absolute neutrophil count $<500 / \mu \mathrm{L}$ ) due to chemotherapy. On admission, he was febrile but otherwise in a good clinical condition with a mild rhinitis, but without cough, dyspnea, or pharyngitis. Blood and urine cultures were taken and nasopharyngeal swabs. Antibiotic therapy was started immediately. One day later (ie, Day 1), the patient proved positive for SARS-CoV-2 and rhinovirus (Table 1). Upon request, he complained taste disorders. Laboratory results showed transfusion-dependent myelosuppression, slightly increased C-reactive protein, procalcitonine, alanine aminotransferase, and a decreased albumin. Ferritin was significantly elevated (Table 2).

Until Day 4, the patient remained well despite recurrent fever. A bone marrow sample was obtained to rule out progression of leukemia, which showed morphologically aplastic marrow without hemophagocytosis or blasts. MRD values were reduced, but still positive compared with the last measurement 32 days before $(5.0 \mathrm{E}-4$ vs. $1.0 \mathrm{E}-3) .{ }^{10} \mathrm{RT}$ PCR for SARS-CoV-2 in the nasopharyngeal swab was positive, but negative in bone marrow and blood (Table 1). In the evening he developed an increasingly productive cough and required oxygen supplementation with a maximal flow of $1 \mathrm{~L} / \mathrm{min}$ to keep saturation above $92 \%$.

On Day 6, the boy was still febrile. All cultures (blood, urine, and stool) were negative. A thoracic computed tomography scan showed predominantly in both lower lobes bilateral ground-glass opacities in peripheral distribution admixed with thickened bronchial walls. These findings were considered as nonspecific with respect to COVID-19 with limited disease extent (Fig. 1).

From Day 10 on the patient remained afebrile. He did not require oxygen supplementation after Day 11. On Day 18 seroconversion with IgG antibodies was observed (Table 1). One day later $>500 /$ microliter neutrophils were counted and the criteria required to continue chemotherapy were met. He continued treatment including a bone-marrow puncture per protocol after 32 days of neutropenia. Compared with the puncture obtained on Day 4 the markers in the MRD evaluation were still detectable, but now below the threshold of quantifiability $(<1.0 \mathrm{E}-4)$.

After continuation of chemotherapy he became neutropenic again on Day 20. Nasopharyngeal swabs and $\operatorname{IgG}$ antibodies remained positive for SARS-CoV-2 repeatedly until Day 59, corresponding with May 29. From then on $\mathrm{IgG}$ antibodies dropped below the threshold for positivity and nasopharyngeal swabs were negative several times until last follow-up in July 2020 (Table 1). 


\begin{tabular}{|c|c|c|c|c|c|c|c|c|c|c|c|c|}
\hline Method & Specimen & $\begin{array}{c}\text { Day 1 } \\
\text { (March 20, } \\
\text { 2020) }\end{array}$ & $\begin{array}{c}\text { Day 3 } \\
\text { (March 22, } \\
\text { 2020) }\end{array}$ & $\begin{array}{l}\text { Day } 4 \\
\text { (March 23, } \\
\text { 2020) }\end{array}$ & $\begin{array}{c}\text { Day } 7 \\
\text { (March } \\
\text { 26, 2020) }\end{array}$ & $\begin{array}{c}\text { Day 13 } \\
\text { (April 1, } \\
\mathbf{2 0 2 0})\end{array}$ & $\begin{array}{c}\text { Day 18 } \\
\text { (April 6, } \\
\text { 2020) }\end{array}$ & $\begin{array}{c}\text { Day 23 } \\
\text { (April 11, } \\
\mathbf{2 0 2 0 )}\end{array}$ & $\begin{array}{c}\text { Day 26 } \\
\text { (April 14, } \\
\text { 2020) }\end{array}$ & $\begin{array}{c}\text { Day 33 } \\
\text { (April 21, } \\
\text { 2020) }\end{array}$ & $\begin{array}{c}\text { Day 41 } \\
\text { (April 29, } \\
\text { 2020) }\end{array}$ & $\begin{array}{c}\text { Day } 49 \\
\text { (May } 7 \text {, } \\
2020)\end{array}$ \\
\hline \multirow[t]{3}{*}{ RT-PCR* } & Nasopharyngeal swab & Positive & - & Positive & Positive & Positive & - & - & Positive & Negative & Positive & - \\
\hline & Blood & - & Negative & Negative & - & - & - & - & - & - & - & - \\
\hline & Bone marrow & - & - & Negative & - & - & - & - & - & - & - & - \\
\hline \multirow[t]{3}{*}{ Antibody $\dagger$} & $\operatorname{IgM}($ Biozek $\dagger$ ) & - & Negative $\dagger$ & - & - & - & Negative $\dagger$ & Negative $\dagger$ & Negative $\dagger$ & - & - & - \\
\hline & $\operatorname{IgG}($ Biozek $\dagger)$ & - & Negative $\dagger$ & - & - & - & Positive $\dagger$ & Positive $\dagger$ & Positive $\dagger$ & - & - & - \\
\hline & IgG ELISA (Euroimmun $\dagger$ ) & - & Negative $\dagger$ & - & - & - & Positive $\dagger$ & Positive $\dagger$ & Positive $\dagger$ & - & Positive $\dagger$ & Positive $†$ \\
\hline $\begin{array}{l}\text { Respiratory } \\
\text { pathogens: }\end{array}$ & $\begin{array}{c}\text { Nasopharyngeal swab using } \\
\text { a multiplex PCR panel } \\
\text { (BioFire } \$ \text { ) }\end{array}$ & $\begin{array}{l}\text { Positive for rhino/ } \\
\text { enterovirus }\end{array}$ & - & - & - & - & - & - & - & - & - & - \\
\hline
\end{tabular}

"Day" refers to day of SARS-CoV-2 illness.

*RT-PCR testing with a laboratory developed test according to the WHO protocol (https://www.who.int/emergencies/diseases/novel-coronavirus-2019/technical-guidance/laboratory-guidance) and AllplexTM 2019-nCoV Assay, Seegene Inc., Seoul, South Korea.

†The antibody test type and value: ELISA Euroimmun (IgG antibodies detectable at a level of 1.2 on Day 18, 1.29 on Day 23, 1.35 on Day $26,1.1$ on Day 41 , and 1.31 on Day 49 by parallel testing of the sera (cut-off 1.1 index) Biozek test (IgG antibodies detectable, IgM antibodies not detectable on Day 18, 23, and 26); antibody tests were performed by means of a lateral flow chromatographic immunoassay for the qualitative detection of IgG and IgM antibodies to COVID-19 (Biozek COVID-19 rapid test, Biozek medical, Appeldoorn, the Netherlands) and ELISA (EUROIMMUN Medizinische Labordiagnostika AG, Lübeck, Germany; https://www.euroimmun.com).

$\$$ The result of respiratory pathogens tested with BioFire Film Array Multiplex PCR panel (BioMérieux Diagnostics, France) for respiratory infections with viruses (adenovirus, coronavirus HKU1, coronavirus NL63, coronavirus 229E, coronavirus OC43, human metapneumovirus, human rhinovirus/enterovirus, influenza A, influenza A/H1, influenza A/H3, influenza A/H1-2009, influenza B, parainfluenza virus 1-4 and respiratory syncytial virus) and bacteria (bordetella parapertussis and pertussis, chlamydia pneumonia and mycoplasma pneumonia).

indicates not tested; RT-PCR, reverse transcriptase-polymerase chain reaction.

\section{TABLE 2. Laboratory Results}

\begin{tabular}{|c|c|c|c|c|c|c|c|c|}
\hline Measure & $\begin{array}{c}\text { Reference } \\
\text { Range }\end{array}$ & $\begin{array}{c}\text { Day 1 } \\
\text { (March 20, 2020) } \\
\end{array}$ & $\begin{array}{c}\text { Day 2 } \\
\text { (March 21, 2020) } \\
\end{array}$ & $\begin{array}{c}\text { Day 3 } \\
\text { (March 22, 2020) } \\
\end{array}$ & $\begin{array}{c}\text { Day } 7 \\
\text { (March 26, 2020) } \\
\end{array}$ & $\begin{array}{c}\text { Day } 14 \\
\text { (April 2, 2020) } \\
\end{array}$ & $\begin{array}{c}\text { Day } 19 \\
\text { (April 7, 2020) } \\
\end{array}$ & $\begin{array}{c}\text { Peak Value } \\
\text { (Day) }\end{array}$ \\
\hline White blood cell count (G/L) & $3-12.5$ & 0.11 & 0.13 & 0.18 & 0.21 & 1.08 & 2.5 & 2.5 (Day 19) \\
\hline Absolute neutrophil count (G/L) & $1.5-7.5$ & 0.01 & 0.01 & 0.01 & 0.06 & 0.19 & 0.52 & 0.52 (Day 19) \\
\hline Absolute lymphocyte count (G/L) & $1-8$ & 0 & 0 & 0 & 0 & 0.62 & 1.44 & 1.44 (Day 19) \\
\hline Red blood cell count $(\mathrm{T} / \mathrm{L})$ & $4-5.3$ & 3.13 & $3.81 *$ & $3.44 *$ & $3.84^{*}$ & $3^{*}$ & $2.63^{*}$ & $3.85^{*}($ Day 8$)$ \\
\hline Hemoglobin $(\mathrm{g} / \mathrm{L})$ & $110-160$ & 94 & $115^{*}$ & $105^{*}$ & $111^{*}$ & $87 *$ & $76^{*}$ & $112 *$ (Day 8 ) \\
\hline Hematocrit (L/L) & $0.33-0.48$ & 0.26 & $0.32 *$ & $0.28 *$ & $0.3^{*}$ & $0.24 *$ & $0.21 *$ & $0.32 *$ (Day 2 ) \\
\hline Platelet count $(\mathrm{G} / \mathrm{L})$ & $150-450$ & 40 & 17 & $47^{*}$ & $36^{*}$ & $38^{*}$ & $121^{*}$ & $121 *$ (Day 19) \\
\hline Alanine aminotransferase $(\mathrm{U} / \mathrm{L})$ & $<50$ & 163 & 95 & 75 & 34 & 49 & 26 & 163 (Day 1) \\
\hline C-reactive protein $(\mathrm{mg} / \mathrm{L})$ & $<5$ & 28 & 47 & 51 & 35 & 3 & $<3$ & 70 (Day 4) \\
\hline Procalcitonine $(\mu \mathrm{g} / \mathrm{L})$ & $<0.1$ & - & 0.24 & - & - & - & - & 0.24 (Day 2) \\
\hline Interleukin-6 (pg/mL) & NP & - & 66 & 70 & 20 & 5 & - & 81 (Day 3) \\
\hline Lactate dehydrogenase (U/L) & $<615$ & - & 274 & 311 & 309 & 417 & 419 & 462 (Day 12) \\
\hline Creatine kinase (U/L) & $<149$ & - & 10 & - & - & - & - & 10 (Day 2) \\
\hline D-dimer $(\mu \mathrm{g} / \mathrm{L})$ & $\leq 500$ & - & 297 & 438 & 428 & 321 & - & 518 (Day 8) \\
\hline Ferritin $(\mu \mathrm{g} / \mathrm{L})$ & $7-140$ & - & - & 1920 & 2288 & 3824 & 3430 & 4213 (Day 15) \\
\hline Albumin $(\mathrm{g} / \mathrm{L})$ & $38-54$ & - & - & - & 24 & 27 & 30 & 30 (Day 19) \\
\hline
\end{tabular}

*Values following transfusions.

- indicates not tested; NP, no reference range provided. 


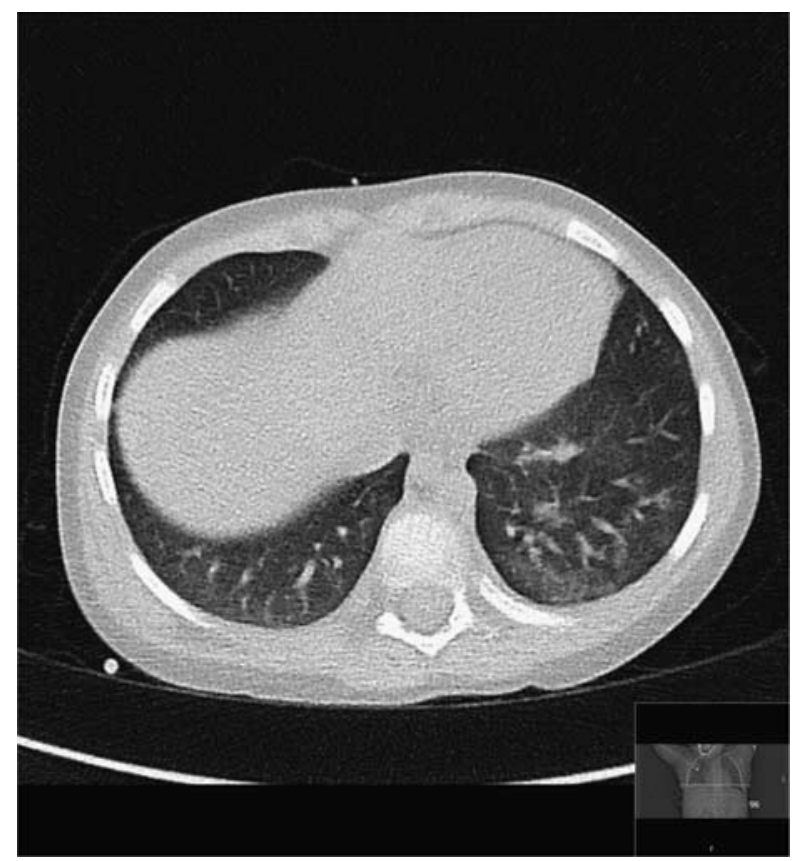

FIGURE 1. From computed tomography scan of the thorax performed at Day 7. Predominantly in both lower lobes presence of bilateral ground-glass opacities in peripheral distribution without subpleural sparing, admixed with bronchial wall thickening and focal alongside linear consolidations. Inset shows that the image is derived from the lower thorax.

\section{DISCUSSION}

Children with acute lymphoblastic leukemia (ALL) are susceptible for infections owing to leukemia-induced and (chemo)therapy-induced immunosuppression. Infections are major causes for treatment-related mortality and the risk of infection is directly related to the severity and duration of neutropenia. ${ }^{11}$ Even if successfully treated, the time required for anti-infective treatment compromises the dose-intensity of (chemo)therapy with a potential impact on the prognosis. In contrast, it is hypothesized that the immune response to infections and/or to vaccinations play a role in the development of ALL. ${ }^{12,13}$ Supporting these hypotheses seem to be, for example, the observations of a reduced incidence of ALL after the outbreak of the first severe acute respiratory syndrome coronavirus in 2003 (SARS-CoV-1) $^{14}$ or after early vaccinations with Bacillus Calmette-Guérin (BCG). ${ }^{13}$

Our patient was most likely infected during neutropenia and lymphopenia in his family cluster. Despite immunosuppression he developed similar symptoms as those reported from immunocompetent children and adults: cough, fever, runny nose, and taste disorders. ${ }^{1-4,15}$ His symptoms, however, remained mild, the deviations of laboratory values from reference ranges were mainly slight and imaging showed just limited disease extent. From the evidence gained from a single patient and from the scarce data in the literature we cannot know whether the mild course of disease was exceptional (eg, due to low virus load), whether it was affected by an inhibited immune response or whether it was typical for children independent from immunosuppression. But it was not influenced by any antiviral therapy. Recently, a beneficial impact of early BCG vaccination on morbidity and mortality of COVID-19 was recognized, but our patient had not received $\mathrm{BCG}$ excluding this confounder. ${ }^{13}$
Biomarkers representing an inflammatory host response such as a decreased albumin and elevated C-reactive protein were altered in a similar manner as in nononcologic patients with COVID-19. ${ }^{4}$ Ferritin was significantly elevated indicating an increased inflammatory response. High ferritin levels were also observed in the child with T-ALL from Wuhan. ${ }^{1,8,9}$ If this is an incidental finding or if immunosuppression inhibited other inflammatory responses or cytokins (eg, interleukin-6) is a matter of speculation. ${ }^{16}$ Of note, biomarkers such as C-reactive protein, which are increased in nonimmunocompromised adults with (bacterial) infections, do not have the same predictive value in pediatric-oncologic patients with fever in neutropenia. ${ }^{17}$ This may represent the inability of the immunocompromised host to react to an infection and may explain why most laboratory values were not severely altered.

Even though SARS-CoV-2 could rarely be detected in the blood we speculated that this might be different in an immunocompromised host with symptomatic disease and high viral replication. ${ }^{18}$ But RT-PCR was negative in the blood and in the bone marrow. ${ }^{15,18,19}$ Viral shedding in the nasopharynx outlasted the presence of clinical symptoms similar to adults without immunosuppression. ${ }^{18}$ It remains to be determined if viral shedding lasts longer in immunocomprised compared with immunocompetent children. At the time when neutropenia was not severe any longer, we found seroconversion to occur in a comparable timeframe as reported in immunocompetent adults. ${ }^{18,20}$ The levels of IgG antibodies were, however, low. This might mirror the observation, that antibody levels are lower in younger patients and in individuals with mild infections. ${ }^{20,21}$ Furthermore, IgG antibody levels became negative 2 months after diagnosis of SARC-CoV-2 infection, possibly because of immunosuppression due to the continuation of chemotherapy.

Our patient recovered with supportive treatment such as oxygen supplementation, transfusions, parenteral nutrition, and antibiotic/antifungal prophylaxis and acquired no secondary infections similar to most pediatric-oncologic patients. Many of them, however, received antiviral therapies. ${ }^{5-7,9}$ No severe side effects of the infection were observed during short-term followup. The course of disease in our patient is therefore a piece of evidence supporting the view that experimental treatments against SARS-CoV-2 may not be necessary if symptoms are moderate even during chemotherapy.

Despite little existing evidence with regard to the mortality of COVID-19 infections in children with cancer, pediatric oncologists consider the mortality from ALL higher compared with that from any infection. ${ }^{11}$ The more relevant threat to our patient was therefore rather treatment delay than infection. Prolonged myelosuppression was the most striking laboratory observation apart from increased ferritin. However, even the treatment delay caused by prolonged neutropenia did not impair the burden of leukemia measured by means of MRD. The intriguing observation that the MRD level was even reduced during the infection while no cytotoxic treatment was administered warrants further investigation.

\section{ACKNOWLEDGMENTS}

The authors thank everyone who contributed to the care of the patient and not least the family.

\section{REFERENCES}

1. Lu X, Zhang L, Du H, et al. SARS-CoV-2 infection in children. $N$ Engl J Med. 2020;382:1663-1665. 
2. Ludvigsson JF. Systematic review of COVID-19 in children shows milder cases and a better prognosis than adults. Acta Paediatr. 2020;109:1088-1095.

3. Onder G, Rezza G. Brusaferro S. Case-fatality rate and characteristics of patients dying in relation to COVID-19 in Italy. JAMA. 2020. Doi: 10.1001/jama.2020.4683.

4. Zhou F, Yu T, Du R, et al. Clinical course and risk factors for mortality of adult inpatients with COVID-19 in Wuhan, China: a retrospective cohort study. Lancet. 2020;395:1054-1062.

5. D'Antiga L. Coronaviruses and immunosuppressed patients: the facts during the third epidemic. Liver Transpl. 2020;26:832-834.

6. Balduzzi A, Brivio E, Rovelli A, et al. Lessons after the early management of the COVID-19 outbreak in a pediatric transplant and hemato-oncology center embedded within a COVID19 dedicated hospital in Lombardia, Italy. Estote parati. Bone Marrow Transplant. 2020:1-6. Doi: 10.1038/s41409-020-0895-4.

7. Hrusak O, Kalina T, Wolf $\mathrm{J}$, et al. Flash survey on severe acute respiratory syndrome coronavirus- 2 infections in paediatric patients on anticancer treatment. Eur J Cancer. 2020;132:11-16.

8. Chen Z, Xiong H, Li JX, et al. COVID-19 with postchemotherapy agranulocytosis in childhood acute leukemia: a case report. Zhonghua Xue Ye Xue Za Zhi. 2020;41:E004.

9. Sun D, Li H, Lu XX, et al. Clinical features of severe pediatric patients with coronavirus disease 2019 in Wuhan: a single center's observational study. World J Pediatr. 2020;16:251-259.

10. van der Velden VH, Cazzaniga G, Schrauder A, et al. Analysis of minimal residual disease by Ig/TCR gene rearrangements: guidelines for interpretation of real-time quantitative PCR data. Leukemia. 2007;21:604-611.

11. O'Connor D, Bate J, Wade R, et al. Infection-related mortality in children with acute lymphoblastic leukemia: an analysis of infectious deaths on UKALL2003. Blood. 2014;124:1056-1061.
12. Greaves M. Infection, immune responses and the aetiology of childhood leukaemia. Nat Rev Cancer. 2006;6:193-203.

13. Hauer J, Fischer U, Auer F, et al. Regional BCG vaccination policy in former East- and West-Germany may impact on both severity of SARS-CoV-2 and incidence of childhood leukemia. Leukemia. 2020;34:2217-2219.

14. Li CK, Zee B, Lee J, et al. Impact of SARS on development of childhood acute lymphoblastic leukaemia. Leukemia. 2007;21: $1353-1356$.

15. She J, Liu L, Liu W. COVID-19 epidemic: disease characteristics in children. $J$ Med Virol. 2020;92:747-754.

16. Mehta P, McAuley DF, Brown M, et al. COVID-19: consider cytokine storm syndromes and immunosuppression. Lancet. 2020;395:1033-1034.

17. Ammann RA, Bodmer N, Hirt A, et al. Predicting adverse events in children with fever and chemotherapy-induced neutropenia: the prospective multicenter SPOG 2003 FN study. J Clin Oncol. 2010;28:2008-2014.

18. Wolfel R, Corman VM, Guggemos W, et al. Virological assessment of hospitalized patients with COVID-2019. Nature. 2020;581: 465-469.

19. Wang W, Xu Y, Gao R, et al. Detection of SARS-CoV-2 in different types of clinical specimens. JAMA. 2020;323: $1843-1844$.

20. Okba NMA, Muller MA, Li W, et al. Severe acute respiratory syndrome coronavirus 2 -specific antibody responses in coronavirus disease 2019 patients. Emerg Infect Dis. 2020;26: $1478-1488$

21. Wu F, Liu M, Wang A, et al. Evaluating the association of clinical characteristics with neutralizing antibody levels in patients who have recovered from mild COVID-19 in Shanghai, China. JAMA Intern Med. 2020. Doi: 10.1001/jamainternmed.2020.4616. 